\title{
The FLARE Index to Treaties extended
}

\section{Dr Peter Clinch, formerly Senior Subject Librarian for Law, Cardiff University, Wales, UK (retired) \\ and \\ Steven Whittle, Information Systems Manager, Institute of Advanced Legal Studies, University of London}

\section{Introduction}

The FLARE Index to Treaties (FIT) <http://ials.sas.ac.uk/treatyindex.htm> which was launched in March 2009 on the Institute of Advanced Legal Studies web server has been extended to cover about a third more treaties and conventions.

In the two years since it was launched the Index has established itself as a valuable finding tool for the international lawyer. It is a fully searchable database now indexing and listing over 2,000 of the most significant multilateral treaties concluded from 1353 onwards and a number of significant bilateral treaties signed between 1353 and 1815.

This article describes the background to the extension and technical aspects of the updated implementation employed to deliver new content and finding features.

More details about the original FIT database will be found in an article published on the LLRX web site in 2009 at:

$<$ http://www.Ilrx.com/features/flareindex.htm>

\section{Why was the FLARE Treaty Index extended?}

When originally launched the Index was based on two groups of material. First, just over 1,000 or so entries relating to significant multilateral treaties concluded between 1856 and 1994 contained in the print publication:

Multilateral Treaties: index and current status, compiled and annotated within the University of Nottingham Treaty Centre by M.J. Bowman and D.J. Harris (London: Butterworths, 1984, tenth supplement, 1994) - hereafter referred to as Bowman \& Harris. Second, about 500 treaties either concluded after the final edition of Bowman \& Harris was published or which were only footnoted in the publication.

Whilst it has always been considered unlikely that the Index could be developed into a comprehensive finding tool for all treaties (see the section 'Which treaties are now included?', below), the addition of significant early treaties would meet the needs of some academic researchers, and the inclusion of a wider selection of recent treaties would serve the needs of both academic and practitioner communities.

\section{Who is behind the extension work?}

The Index to Treaties was initially developed at the Institute of Advanced Legal Studies (IALS), School of Advanced Study, University of London with the support of a development award from the Vice Chancellor as an important 
addition to the Institute's portfolio of freely-available national online services for law. The Foreign Law Research (FLARE) Group

$<$ http://ials.sas.ac.uk/flare/flare.htm>, which encouraged the initial development of FIT, agreed that there was scope to make the Index more comprehensive. The Group is chaired by the Librarian of the Institute of Advanced Legal Studies (IALS) and this institution made available modest funds for a seconded member of the Group, Dr Peter Clinch, formerly of Cardiff University, and Steven Whittle, of IALS to undertake the extension project.

\section{Which treaties are now included?}

The original 1,500 treaties harvested from Bowman \& Harris were supplemented with titles obtained from a number of sources listed in the original LLRX article cited above. For the extension, details of 293 key treaties concluded between 1353 and 1856 were added (including a small number of key bilateral treaties concluded between 1353 and 1815), plus 203 multilateral treaties of more recent date mentioned in the following:

Index of British Treaties, 1101-1988, various compilers (London, HMSO, 1971-1992)

Index to Multilateral Treaties, edited by Vaclav Mostecky (Cambridge: Harvard Law School Library, 1965)

Catalogue of Treaties 1814-1918 (Washington: Government Printing Office, 1919).

In addition the Index includes, with links:

- all International Labour Organization conventions <http://www.ilo.org/ilolex/english/convdisp1.htm>

- the entire European Treaty Series of the Council of Europe $<$ http://conventions.coe.int/>

- all treaties available on the web concluded by the Organization of American States <http://www.oas.org/DIL/treaties_and_agreements.htm>

- and every multilateral treaty printed in the Australian Treaty Series, with links to the AUSTLII Australian Treaties Library $<$ http://www.austlii.edu.au/au/other/dfat/>

The Index does not include any bilateral treaties concluded after 1815. Clearly it would be desirable to create a comprehensive database. However, the magnitude of the task may be illustrated by the fact that the World Treaty Index, compiled by Peter H. Rohn (Santa Barbara, California, 1984), which covers all types of treaty signed between only 1900 and 1980, comprises over 44,000 entries. The compilers estimate that during this period the number of bilateral treaties outnumbers multilaterals by a ratio of about 10 to 1 . 
As a starting point, the FLARE Group has considered creating a further extension to the Index to include bilateral treaties to which the UK is a party. The Group acknowledges that the task would be a considerable challenge requiring close cooperation and liaison with the Foreign and Commonwealth Office. This development remains only a proposal for the time being.

\section{How the Index database has been extended - Technical background} The extension project has provided an opportunity to refresh the look and enhance some of the finding features of the Flare Index to Treaties.

The Index runs from the IALS web server using customised standard applications, currently Inmagic's < http://www.inmagic.com/> DB/Text and Web Publisher Pro database software - marketed in the UK by Soutron limited $<$ http://www.soutron.com/>.

A working database designed in Microsoft Access provides a ready and easily exchangeable means of collating and expanding the treaty data. Periodic copies of the data are exported from MS Access and loaded into a DB/text database with matching field structure.

Our experience with the flexible and scalable Inmagic applications continues to help us target limited funds in essential data building and in meeting the needs of legal researchers. The form, nature and evolution of treaty texts and often-requested facts about the documents inform the structure of the database and choice of key access points. We are able to design and adjust search screens, results tables and detailed records modifying displayed fields, indexed fields and sort order and external linking to accommodate new content.

Web Publisher Pro (version 12) on the IALS server in conjunction with Microsoft Internet Information Server (IIS) publishes the Index to Treaties freely on the web - alongside a number of other IALS created online services for law and legal research aids such as: the FLAG Foreign Law Guide $<$ http://ials.sas.ac.uk/flag.htm> and the Eagle-i Internet Portal for Law <http://www.ials.sas.ac.uk/eagle-i.htm>.

XML output capability means we are able to explore options for RSS feeds of new additions to the database and the system includes URL checking facilities to help us trace broken web links for treaty texts in each of the URL format fields.

\section{How the web interface is structured - Using the Flare Index to Treaties} As before, the Index to Treaties web interface comprises: a search screen, results table and individual record display.

\section{Search screen}

The search screen is a simple form designed to help locate relevant treaty details from as much or as little initial information as a user has available. You can type any word, combination of words or phrase in a free text search box 
which covers key fields in the database such as official title, popular title, other title and keywords.

There are also separate search field options to search by words known to be in the treaty title, or the year or date when the treaty was concluded or the place where the treaty was concluded.

Once you have prepared a query, you just click on the Submit Query button or press the Return/Enter key to perform that search. A Reset button clears the form to start a fresh query.

In the example below, the only information known is that Helsinki is the place where the treaty was concluded.

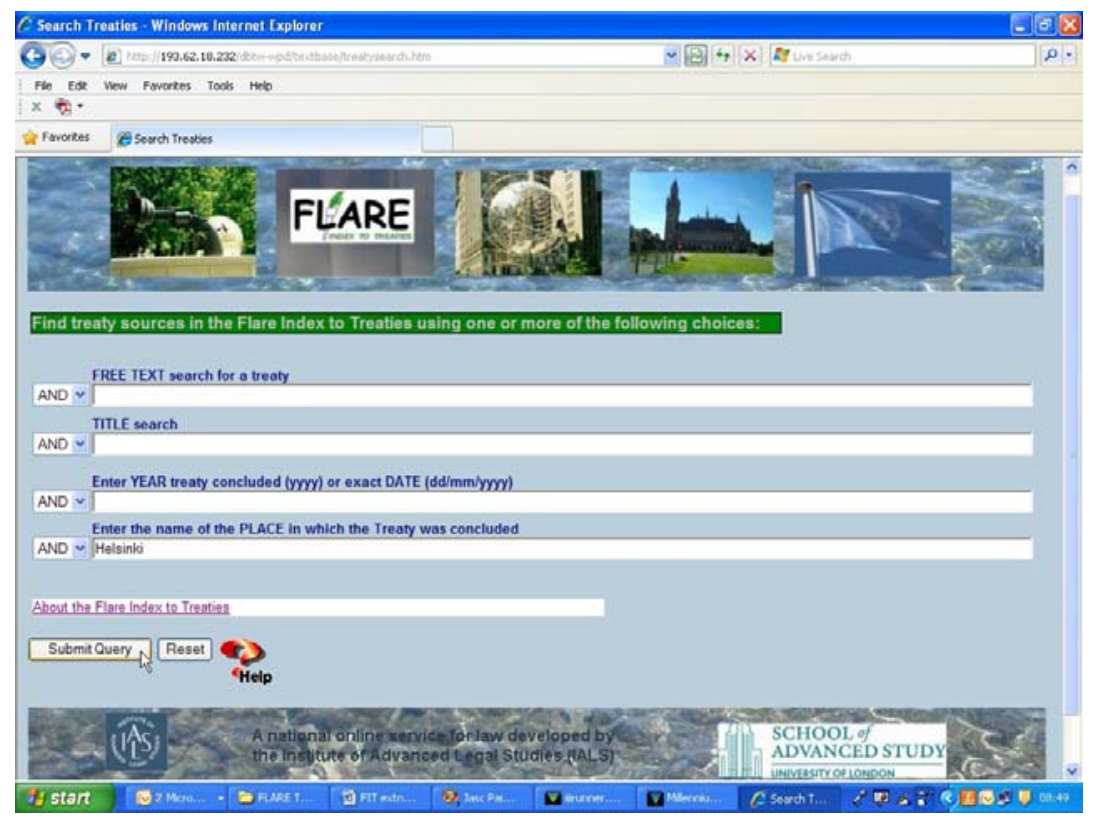

\section{More complex queries}

Our approach has been to keep the search interface as simple as possible while building in the capability to support more complex and sophisticated search requirements.

A Help option offered by the question mark button at the foot of the search form suggests search strategies and examples of how to fine-tune a search. Boolean search functionality is available within individual fields or between different fields to expand or narrow the focus of a particular search. Within a field the Boolean logic operators AND, OR and NOT are represented by the characters \&, $I, !$ to connect search terms and truncation and proximity searching is available. Additionally, Boolean search options are provided between fields in the database structure. Dropdown menus ahead of each field enable you to select the connectors AND, OR or NOT and combine searches involving several fields at the same time. 
The extended Index now includes a new Advanced search screen with options to browse as well as search the database by Year concluded, Place concluded and Country or organisation of Deposit. There is also a facility to find bilateral treaties included in the Index by entering the details of one or more of the Parties to the treaty.

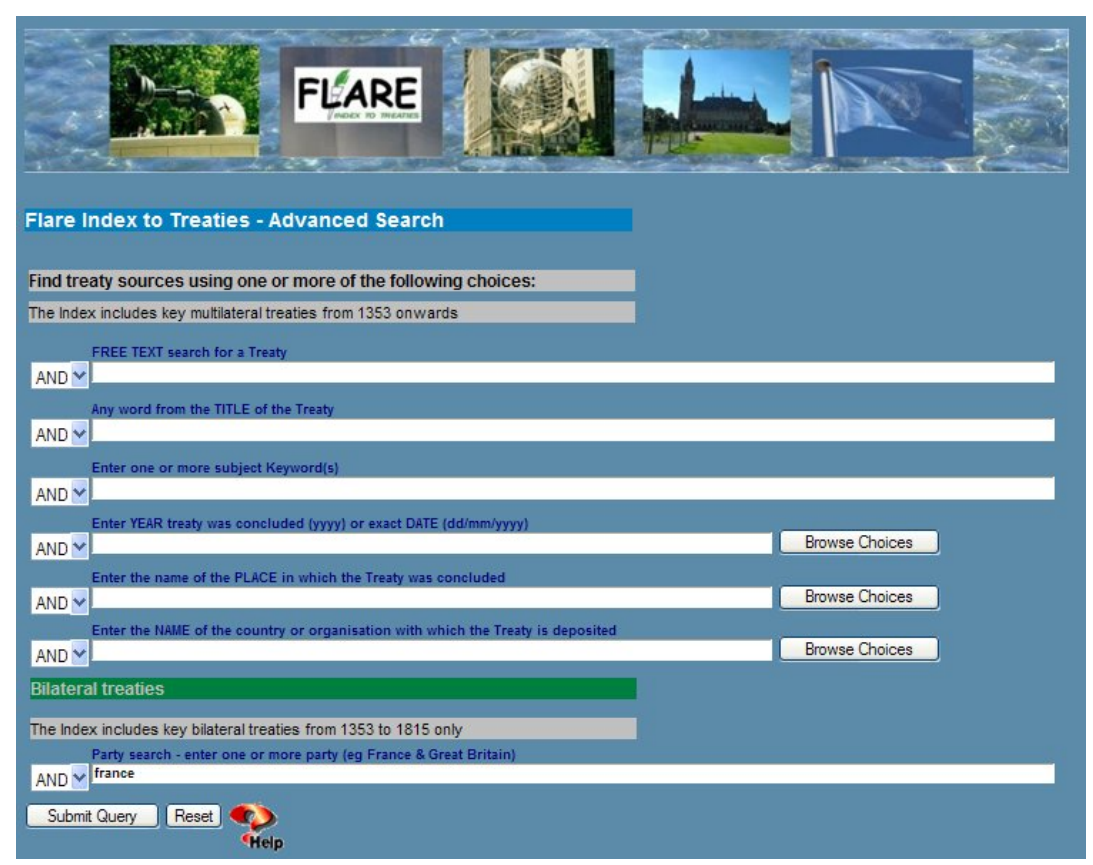

\section{Results Table}

The results of a successful search from the simple or advanced screens are presented in a table displaying the title of the treaty, date concluded, and place concluded, batched in groups of ten entries, with an indication of the number of records the search has retrieved. The treaties are listed by title in date order with the most recent dates first. The occurrence of the search term(s) used is highlighted in bold text in each of the records presented. Buttons to aid navigation between the next and previous set of records are displayed at the top and bottom of the table. Use of the browser Back button allows modification of an existing search. 


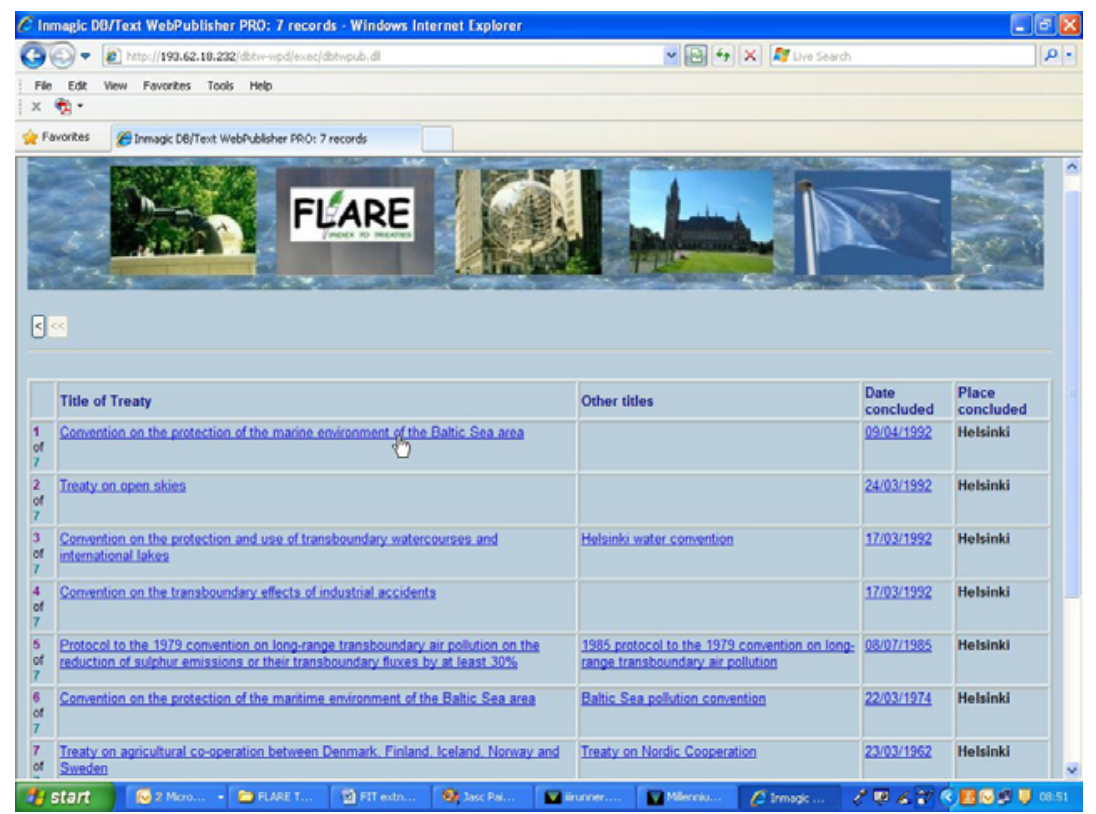

The Results Table offers a link from the treaty title and/or date concluded to the full record entry for each treaty.

\section{Treaty Record}

A full record includes: popular, official and alternative treaty titles, details of the date concluded, place concluded, published sources and where the treaty is available on the Internet, the records have embedded links to reliable and stable web versions of the treaty, and where appropriate links to value added information on the treaty offered by the American Society of International Law's EISIL service <http://www.eisil.org/>. A developments link takes researchers through to related and updating materials provided on the web by the organisation responsible for drawing up the treaty. The navigation buttons above and below the treaty record again enable you to move to the next or previous record in the set. Search results can be printed using standard web browser printing options from either the results display or full treaty record.

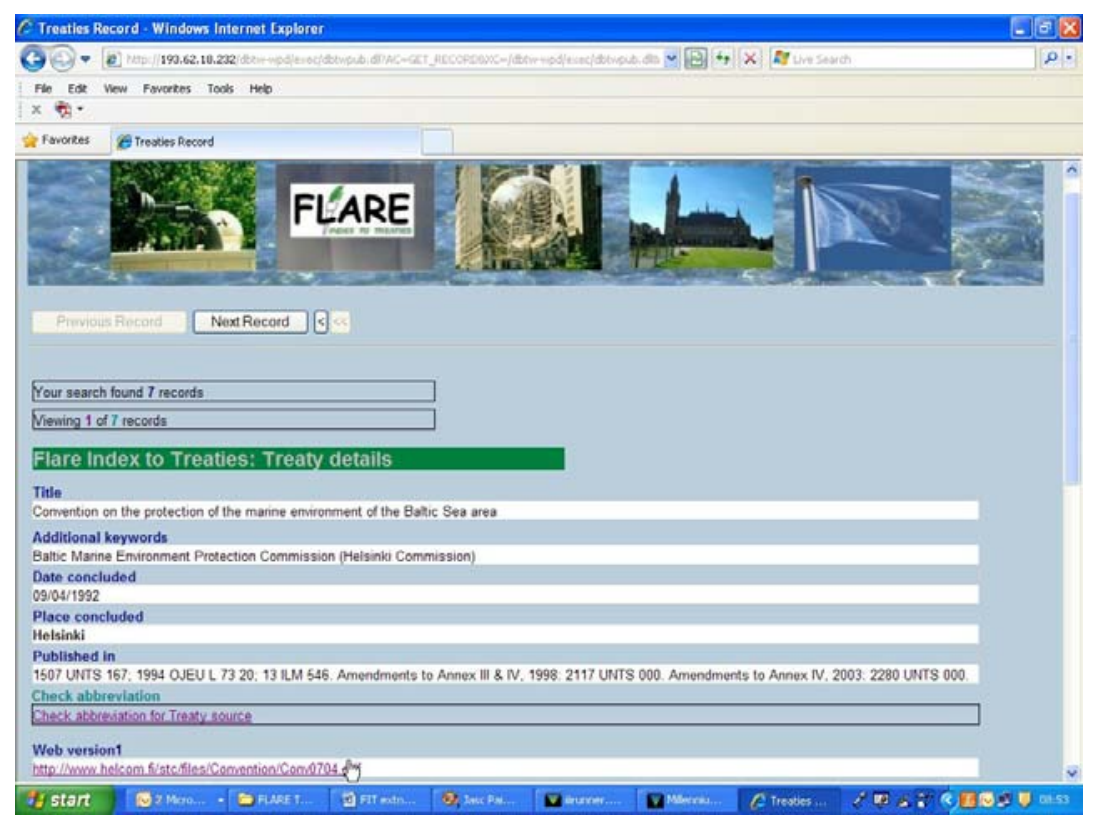




\section{Checking abbreviations}

The treaty records include a facility to check the meaning of abbreviations cited for treaty sources, through a link to a secondary database, containing entries expanding the meaning of abbreviations referenced in the published sources field. The extended Index now offers enhanced abbreviation browse and find features.

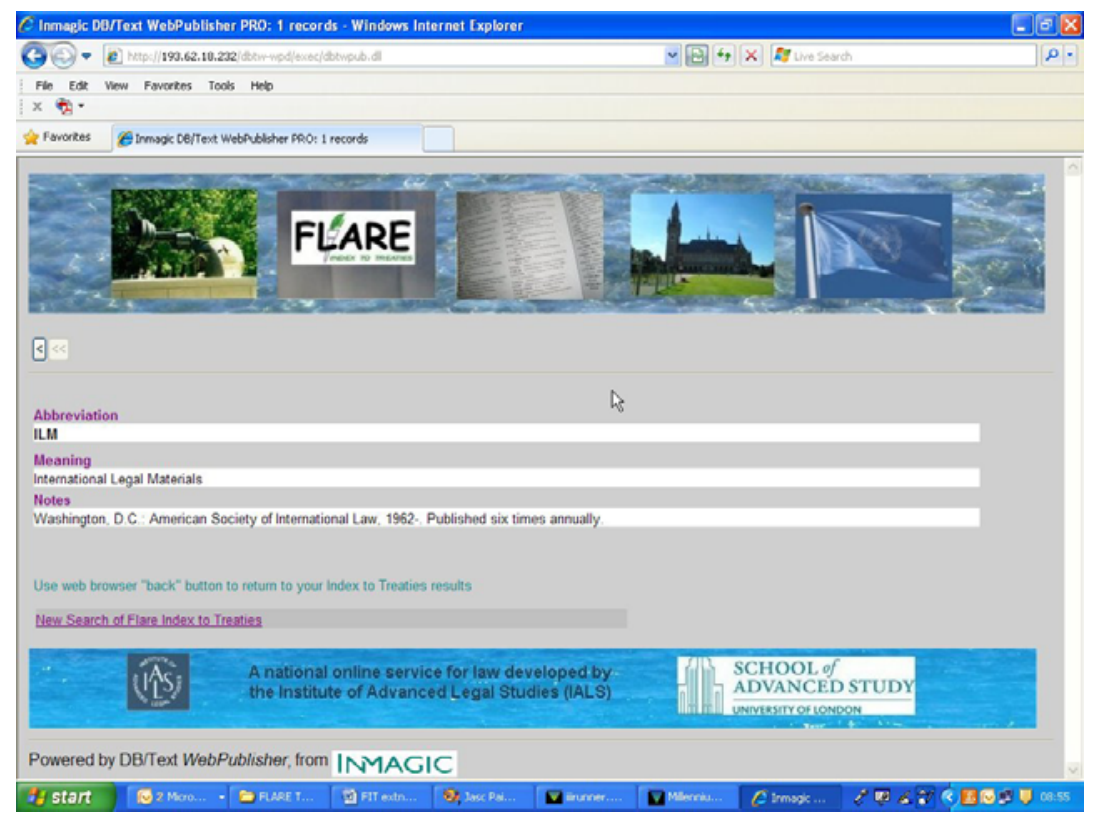

\section{Smart linking to the Flare Index to Treaties}

The current generation of web 2.0 enabled interactive library discovery catalogues like Encore <http://www.iii.com/products/encore.shtml> from Innovative and Primo from Ex Libris $<$ http://www.exlibrisgroup.com/category/PrimoOverview> provide contextsensitive links to other relevant web-based resources, making intelligent suggestions for further exploration which can include the Index to Treaties.

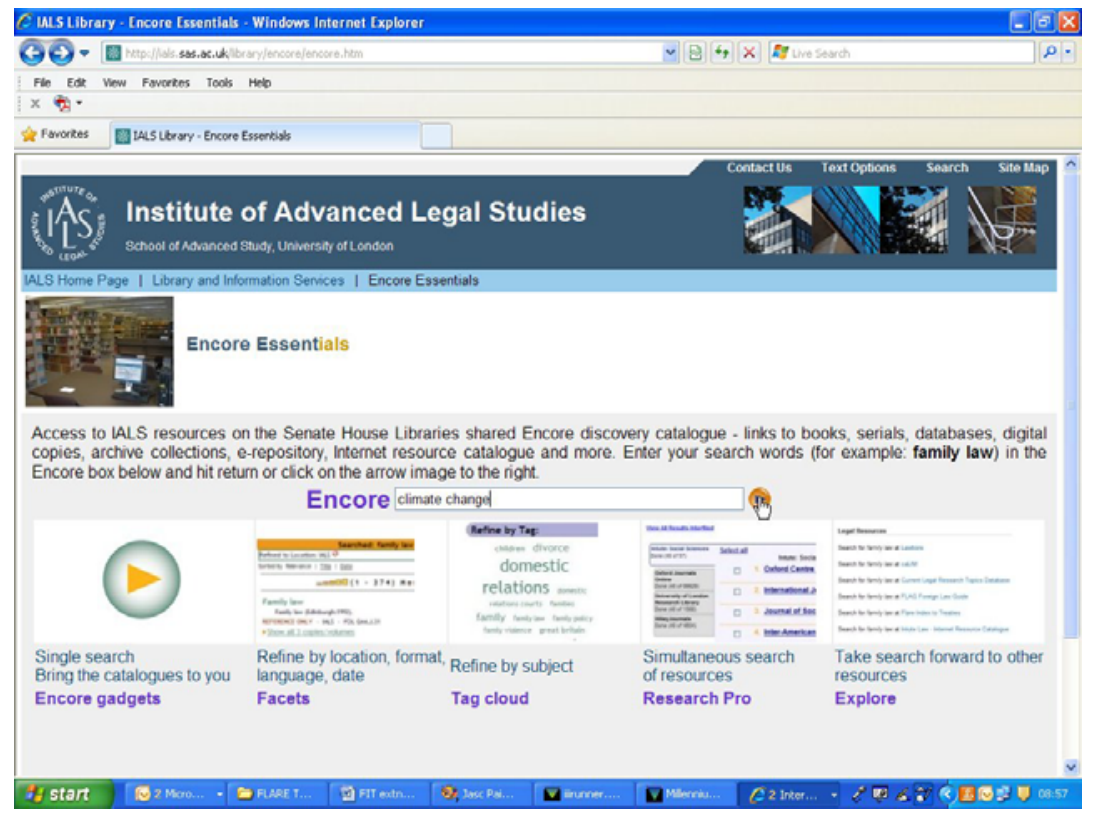


In this example a title search for "climate change" through the Encore view of the IALS Library catalogue <http://ials.sas.ac.uk/encore.htm> is taken forward to a selection of other law resources on the web, presented through the "search other resources" button and resource selection panel.

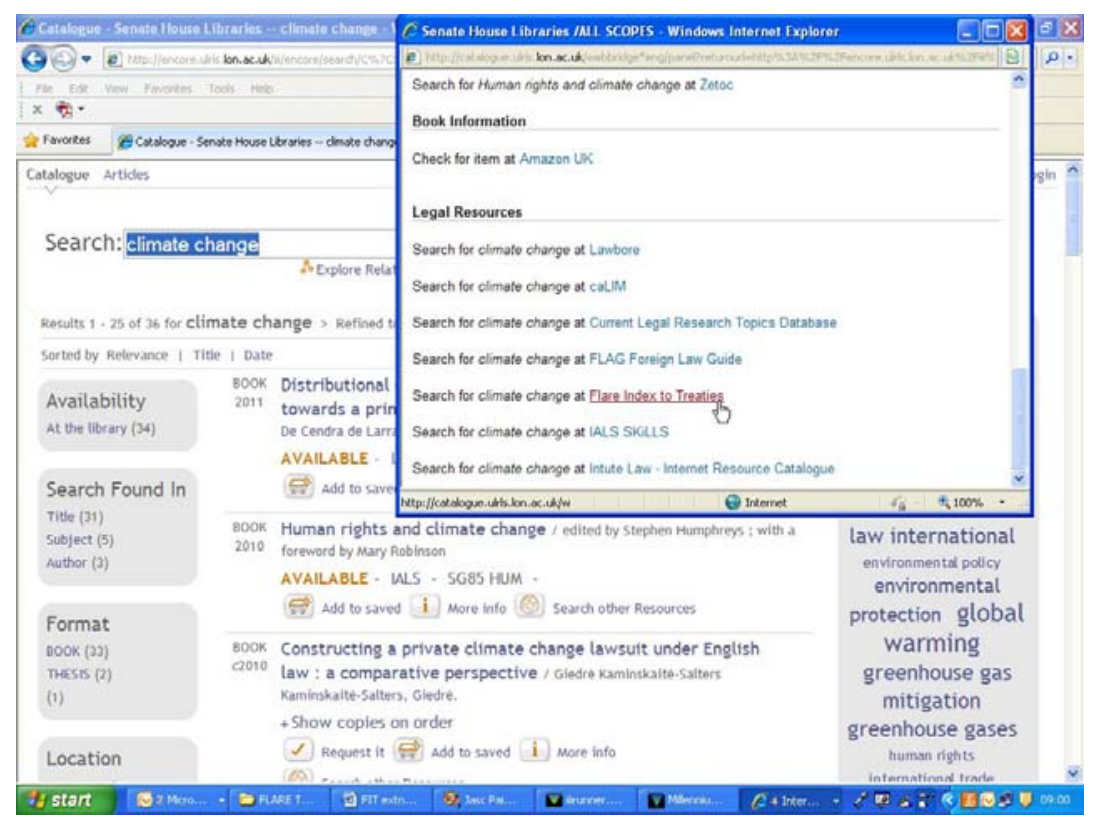

Clicking on the Flare Index to Treaties link option performs the search on the Index and opens the FIT results table without leaving the original Encore results screen.

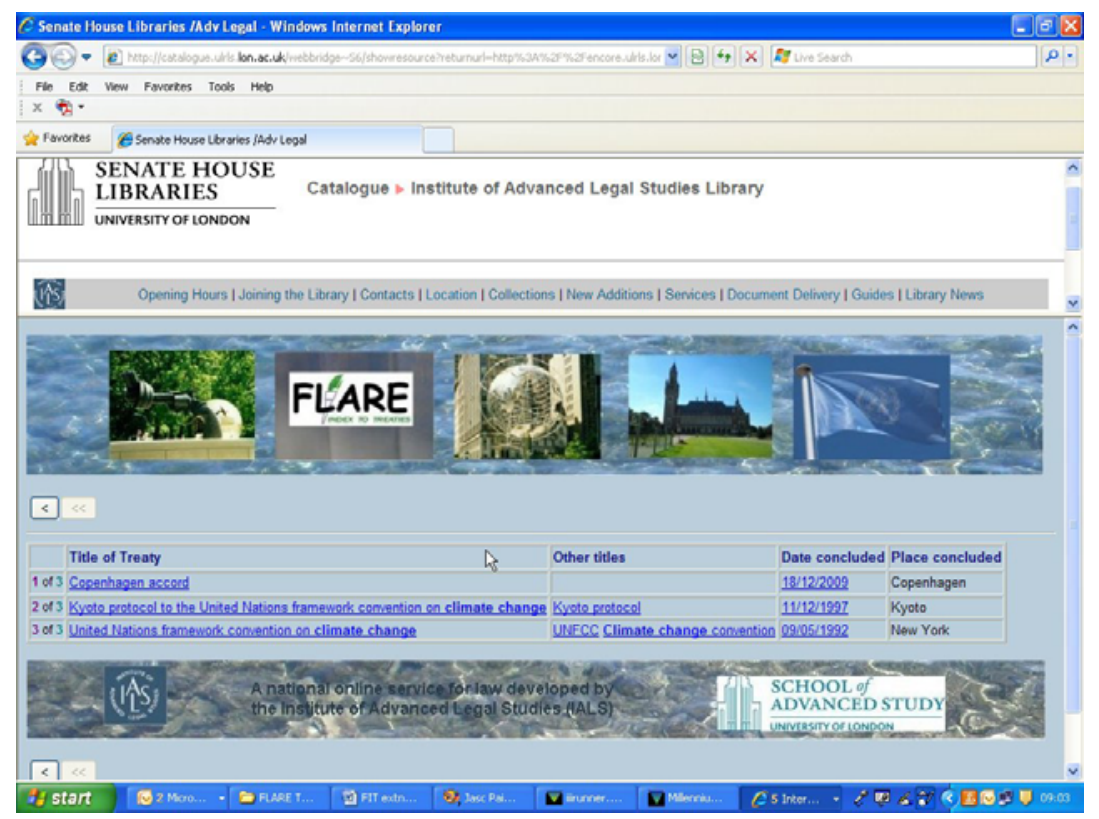




\section{Impact and further development of the Index}

The extended Flare Index to Treaties aims to provide an improved research tool to complement existing sources, aiding scholars and students, lawyers and librarians in researching the international law of treaties - whether they are new or experienced in the field.

Since its launch in 2009 responses to the Index have been very encouraging. It has established cross-sector interest and relevance and we have received helpful feedback from international academic lawyers referencing the Index in new editions of their works, professional organisations including the Organisation of South African Law Libraries (OSALL) $<$ http://www.osall.org.za/ > promoting the service to their members, and potential collaborators such as WorldLIII < http://www.worldlii.org/ > looking at ways to include the service in emerging co-operative initiatives.

In particular, recognition of the significance of the Index by the British and Irish Association of Law Libraries (BIALL) through the honour of the Wallace Breem Award kindly given to Steven Whittle in 2010 was very gratifying.

In 2011 demonstrations of the Flare Index to Treaties featured in a series of IALS "roadshow" visits at law schools across the UK. We were pleased to be able to raise awareness of our online legal research tools and show how the Index can assist with checking references, writing papers and preparing teaching materials on visits to Belfast, Birmingham, Brunel, Essex, Liverpool, Norwich, and Nottingham and the College of Law in London. Further visits and presentations are planned later in the year.

Who do I contact with comments, queries and reactions to the Index? Your reactions to and comments on the Index and suggestions for further developments are welcomed and should be sent to Steven Whittle at steven.whittle@sas.ac.uk

Peter Clinch

Steven Whittle

August 2011 